\title{
Beslenme Tedavisinin Glisemik Kontrol, Vücut Ağırlığı Yönetimi ve Kardiyovasküler Hastalık Risk Profiline Etkisi
}

\section{The Effect of Nutrition Therapy on Glycemic Control, Body Weight Management and Cardiovascular Disease Risk Profile}

\section{Aylin Açıkgöz ${ }^{1}$}

Geliş tarihi/Received: 11.03.2019 • Kabul tarihi/Accepted: 18.06.2019

\section{ÖZET}

Diyabet, küresel olarak artan bir prevalansta yaygın görülen kronik bir hastalıktır. Tıbbi beslenme tedavisi diyabetin yönetiminde tamamlayıcı bir role sahiptir ve tanı sonrasında uygun beslenme tedavisi ile izlenen bireylerde metabolik kontrolün sağlanmasına katkı sağlamaktadır. Diyabetli bireylerde vücut ağırlığındaki \%5-10’luk kaybın glisemik ve metabolik kontrolün iyileştirilmesi için gerçekçi bir hedef olduğu belirtilmektedir. Beslenme önerileri, glisemik kontrolün ve diğer metabolik sonuçların iyileştirilmesi üzerinde olumlu bir etki sağlamaktadır. Ayrıca klinik çalışmalar, beslenme tedavisinin, diyabetin önlenmesinde de etkinliği olduğunu kanıtlarla göstermektedir. Bu derleme yazının amacı, beslenme tedavisinin ve farklı diyet yaklaşımlarının glisemik kontrol, vücut ağırlık yönetimi ve kardiyovasküler hastalık risk profili üzerindeki etkilerini değerlendirmektir.

Anahtar kelimeler: Diyabette beslenme tedavisi, glisemik kontrol, vücut ağırlı yönetimi, kardiyovasküler hastallk risk profili

\begin{abstract}
The epidemic of diabetes is a growing prevalence globally. Medical nutrition therapy has a complementary role in the management of diabetes and contributes to metabolic control in individuals who are followed up with appropriate nutritional therapy after diagnosis. Weight loss of 5\% to $10 \%$ is a realistic goal for improving glycemic and metabolic control in people with diabetes. Nutritional recommendations provide a positive effect on the improvement of glycemic control and other metabolic outcomes. Clinical trials also provide evidence for the effectiveness of nutritional therapy in the prevention of diabetes. The purpose of this review is to appraise the effects of nutritional therapy and different dietary approaches on glycemic control, body weight management, and cardiovascular disease risk profile.
\end{abstract}

Keywords: Nutrition therapy in diabetes, glycemic control, body weight management, cardiovascular disease risk profile

\section{GİRIŞ}

Uluslararası Diyabet Federasyonu'nun (International Diabetes Federation [IDF]) Diyabet Atlası verilerine göre; 2017 yılında dünyada 18-99 yaş aralığındaki bireylerin \%8.8'i (451 milyon) diyabet tanısı almış iken, bu oranın 2045 yılında \%9.9 (693 milyon) olacağı tahmin edilmektedir. Ayrıca aynı yaş grubu için 2017

1. İletişim/Correspondence: Hacettepe Üniversitesi, Sağllk Bilimleri Fakültesi, Beslenme ve Diyetetik Bölümü, Ankara, Türkiye

E-posta: aylinn@hacettepe.edu.tr • 다 https://orcid.org/0000-0002-8847-9305 
yılında dünyada yaklaşık olarak 5 milyon bireyin (20-99 yaş) diyabet kaynaklı nedenler ile yaşamını yitirdiği bildirilmiştir. Aynı zamanda diyabetli bireylerin sağlık harcamalarının dünya genelinde 850 milyon dolar olduğu belirtilmektedir (1).

Araştırmalar, global epidemi boyutunda olan diyabetin yönetimindeaçlık kan glukoz değerindeki her $1 \mathrm{mmol} / \mathrm{L}$ 'lik azalmanın kardiyovasküler (KV) hastalık riskinde \%23 azalma sağladığını (2), HbA1c'deki her \%1'lik artışın mortalite ve KV olay riskinde \%20-30'luk artışa neden olabildiğini göstermektedir (3). Benzer şekilde hafif şişman ve şişman bireylerde vücut ağırlığındaki \%5-10'luk kaybın, glisemik kontrolde iyileşme ve KV hastalık risk faktörlerinde azalma sağladığını bildirilmiştir $(4,5)$. Beslenme tedavisinin özellikle de diyetisyenler tarafindan sağlanan beslenme tedavisinin glisemik kontrol ve diğer metabolik sonuçların iyileşmesinde olumlu etkiler sağladığı literatürde yer almaktadır (6-8). Amerikan Diyabet Birliği (American Diabetes Association-ADA) beslenme tedavisinin, tüm tip 1 ve tip 2 diyabetli bireylerin tedavi planlarının etkili bileşeni olduğunu belirtmiştir. Bu doğrultuda beslenme tedavisinin amacl; sağlıklı beslenme alışkanlıkları kazandırmak, glukoz, lipit ve kan basıncı hedeflerine ulaşmada yardımcı olmaktır (9). $\mathrm{Bu}$ derleme yazının amacı; beslenme tedavisinin ve farklı diyet yaklaşımlarının glisemik kontrol, vücut ağırlık yönetimi ve KV hastalık risk profiline etkisini güncel literatürler eşliğinde irdelemektir.

\section{Diyabetik Bireylerde Tıbbi Beslenme Tedavisinin Etkileri}

Diyabet tipi, süresi ve tedavinin başlangıcındaki HbA1c düzeylerine bağlı olarak değişiklik göstermekle birlikte, alanında uzman diyetisyenler tarafindan sağlanan beslenme tedavisinin HbA1c düzeylerinde yaklaşık olarak \%1-2 (-\%0.23 ile -\%2.3 arasında, $\mathrm{p}<0.05)$ azalma sağladığı belirtilmiştir $(9,10)$. Optimal kan glukoz kontrolü olmayan (HbA1c >\%7), kronolojik yaşı $<70$ yıl, ortalama diyabet yaşı 9 yıl olan, tip 2 diyabet tanılı bireyler ile yürütülmüş bir çalışmada, ilk ay 2 kez, beş ay ayda 1 kez olmak üzere altı ay boyunca diyetisyen takibiyle sağlanan beslenme tedavisinin HbA1c düzeylerinde \%0.4 azalma sağladığıvebuoranın istatistiksel olarak anlamlı olduğu bildirilmiştir. Aynı çalışmada ek olarak, bireylerin vücut ağırlığı, beden kütle indeksi (BKİ) ve bel çevresi ölçümlerinde de altı ay sonunda anlamlı azalma saptandığı belirtilmiştir. Araştırmacılar, çalışmanın tartışma bölümünde beslenme tedavisinin oral antidiyabetik ilaç veya insülin tedavisinden daha ucuz olduğunu ve medikal tedavi ile glisemik kontrolde sağlanan iyileşmeye benzer hatta daha fazla etkisi olduğunu ifade edilmiştir (11). Randomize kontrollü çalışmaların incelendiği bir sistematik derlemede (26 çalışma, $\mathrm{n}=5500$ ) ise 1 . basamakta diyetisyenlerden sağlanan beslenme müdahalesinin bireylerin diyetlerinin kalitesinde, diyabet çıtılarında (kan glukozu, HbA1c) ve vücut ağırlık kaybı çıktılarında (vücut ağırlığında ve bel çevresi ölçümlerinde) iyileşme olduğu belirtilmiştir. Ancak derleme makalede değerlendirilen araştırmalar, plazma lipit düzeyleri ve kan basıncı ile ilgili sonuçlara ulaşmada tek başına diyetetik danışmanlığının etkinliği konusunda tutarlı bir destek sağlamamaktadır (8). Beslenme önerilerinin hastanede yatış sıklığı üzerine etkilerini araştıran bir başka çalışmada, 18000 diyabet tanılı birey yaklaşık olarak dokuz yıllık takip süreçlerinde değerlendirilmiş ve gerçekleşen her diyetisyen görüşmesinin yılda her 100 birey için hastane yatışında 4.7 günlük azalma sağladığı belirtilmiştir $(\mathrm{p}<0.05)(12)$.

\section{Diyabette Hangi Tıbbi Beslenme Tedavisi Yaklaşımı veya Besin Ögesi Bileşeni Metabolik Parametreler Üzerine Daha Etkilidir?}

Uygulanan beslenme tedavilerinde; enerji/yağ alımını azaltmak, karbonhidrat sayımı, basitleştirilmiş öğün planları, sağlıklı besin veya değişim seçenekleri, insülin/karbonhidrat oranının kullanımı, fiziksel aktivite ve davranışsal strateji yaklaşımları kullanılmaktadır. Tip 2 diyabetli bireyler için enerji alımının azaltılması, tip 1 diyabetli bireyler için ise karbonhidrat sayımı beslenme müdahalelerinin odak noktasını oluşturmaktadır (10). Diyabetli bireylerin bireye özgü tıbbi beslenme tedavisi (TBT) yaklaşımı 
ile takip edilmeleri ve beslenme tedavisinin tercihen diyabette TBT'nin bileşenlerini iyi bilen uzman diyetisyenler tarafindan yapılması ADA'nın önerileri arasında yer almaktadır (9).

Düşük karbonhidrat içerikli diyetler, çalışmaların en fazla yoğunlaştığı diyetlerdir. Meta-analiz sonuçlarına göre; düşük karbonhidrat içerikli diyetler kısa dönemde olumlu etkiler gösterse de, uzun dönemde istatistiksel olarak anlamlı farklılık yaratmamaktadır (13-16). On bir randomize kontrollü çalışmanın incelendiği bir meta-analizde de, düşük karbonhidratlı (20-30 g/gün veya enerjinin <\%20'si karbonhidrat içerikli) diyetler, düşük yağlı (enerjinin <\%30’u) diyetler ile karşılaştırılmış ve çalışma sonucunda vücut ağırlığı kaybında her iki diyet ile benzer sonuçlar saptanırken, düşük karbonhidratlı diyetlerin düşük dansiteli lipoprotein (LDL) kolesterol düzeylerinde artışa neden olduğu vurgulanmıştır (17). On yedi çalışmanın incelendiği bir başka metaanalizde ise düşük karbonhidratlı diyetlerin tüm nedenlere bağlı ölüm riskini yaklaşık \%31 oranında artırdığı belirtilmiştir (RR:1.31, 1.07-1.59, p<0.05) (18). Hatta Huntriss et al. (16) çalışmalarında yedi randomize kontrollü çalışmanın $(n=2204)$ sonucunu değerlendirmiş ve $<50 \mathrm{~g}$ karbonhidrat içeren diyetlerin toplumda uygulanabilmesinin inandirıcı bir hedef olmadığını vurgulamıştır. Rehberler de çalışma sonuçlarını desteklemekte ve fazla kilolu ve obez diyabetli bireylerin TBT’sinde < 130 g/gün karbonhidrat alımını önermemektedir. $\mathrm{Bu}$ oranlar gebelik dönemindeki diyabetli bireyler için >170 g/ gün, emziklilik dönemindeki diyabetli bireyler için ise $>210 \mathrm{~g} /$ gün karbonhidrat alımının sağlanması yönündedir. Aynı zamanda rehberler düşük karbonhidrat (<130 g/gün veya enerjinin <\%26'sı) veya çok düşük karbonhidrat içerikli (<50 g/gün veya enerjinin <\%10'u) diyetlerin kullanılmamasinı da vurgulamaktadır $(9,19)$.

Literatürde düşük veya yüksek glisemik indeks (Gİ) ve glisemik yük (GY) değerlerine sahip diyetlerin glisemik yanıt ve $\mathrm{KV}$ risk parametreleri üzerine etkilerini inceleyen çalışmalar da mevcuttur (2022). Düşük ve yüksek Gİ içerikli diyetlerin HbA1c ve fruktozamin düzeyleri üzerine etkisini değerlendiren bir sistematik derleme ve meta-analizde 18 randomize kontrollü çalışma ( $n=840,2-114$ hafta süreli) araştırma kapsamına alınmış olup, düşük Gí içerikli diyetlerin, HbA1c $(-\% 0.42, \mathrm{p}<0.01)$ ve fruktozamin $(-0.44, \mathrm{p}=0.02)$ düzeylerinde azalma sağlayarak glisemik kontrol üzerinde faydalı etki gösterdiği belirtilmiştir (20). Benzer şekilde dokuz randomize kontrollü çalışmanın ( $n=705,2$ hafta-22 ay süreli) incelendiği bir başka metaanalizde, düşük Gİ içerikli diyetlerin uygulanması ile HbA1c ve açlık kan glukozu düzeylerinde istatistiksel olarak anlamlı düzeyde azalma gözlenmiştir (21). Toplam 11 randomize kontrollü çalışmanın $(n=402$, 1-12 ay süreli) dahil edildiği yüksek ve düşük Gİ içerikli diyetlerin karşılaştırıldığı bir diğer meta-analizde de HbA1c, total ve LDL kolesterol düzeylerinde azalma bildirilmiştir $(p<0.05)$ (22). Yapılan çalışmalar da düşük Gİ içerikli diyetlerin olumlu etkilerini bildirmektedir, ancak belirtilen olumlu etkilerin oluşumunda yüksek posanın mı, düşük Gİ içeriğinin mi daha etkili olduğunu söylemenin mümkün olmaması çalışmalardaki en büyük sinırlılığı oluşturmaktadır (20-22). Bununla birlikte tüketilen besin miktarının fazlalığının, pH’sının, posa, protein ve yağ içeriğinin, nişasta türünün ve pişirme yöntemi ve süresinin de besinlerin Gİ değerini değiştirerek kan glukoz cevabını etkileyebileceği unutulmamalıdır (23).

Gıda ve Tarım Örgütü (Food and Agriculture Organization [FAO]); diyabetik bireylerde GI'in, kan glukoz yanıtını etkileyen kullanışlı bir gösterge olduğunu belirtirken (24), ADA; diyabetik bireylerin posa içeriği yüksek, düşük Gİ içerikli sebze ve meyveler, tam tahıl ürünleri gibi karbonhidrat kaynaklarının tüketimini tercih etmelerini önermektedir (19). Ek olarak ADA, diyabetik bireylerin diyetlerinde yer alan şeker eklenmiş düşük posa içerikli, glisemik yükü yüksek besinleri özellikle posa içeriği yüksek, glisemik yükü düşük besinlerle değiştirmesi önerisini de vurgulamaktadır (19).

Vejetaryen beslenmenin etkilerinin araştırıldığı çalışmalarda da, vejetaryen beslenme tarzının dislipidemide düzelme (25), iskemik kalp hastalığı, KV ve serebrovasküler (SV) hastalıkların mortalitesinde 
azalma (26) sağladığı bildirilmektedir. Buna karşın, 2017 yllında yayınlanan bir meta-analizde vejetaryen beslenme tarzının, BKİ, total kolesterol, LDL kolesterol ve kan glukoz düzeylerinin azalmasinda etkili olabileceği ancak KV ve SV hastalık görülme sıklığı üzerinde istatistiksel olarak fark yaratmadığı belirtilmiştir (27). Aynı meta-analizde vejetaryen diyetlerin lipit profili üzerine olan olumlu etkisinin bu diyet modelinde toplam ve çözünür posa, yağlı tohumlar, soya ve bitki sterolleri alımının yüksek, doymuş yağ tüketiminin ise düşük düzeylerde olmasından kaynaklanabileceği vurgulanmıştır (27). Hem düşük Gİ, hem de vejetaryen diyet uygulamalarının gösterdiği olumlu sonuçlarda etkisi olan posanın alım düzeyini, ADA tip 2 diyabet yönünden riskli bireyler ve diyabetli bireylerde her 1000 kkal/gün için 14 g olarak önermektedir (9).

Goday et al. (28) çalışmalarında tip 2 diyabetli bireylerde çok düşük enerjili diyet (Very Low Calorie Diet [VLCD]) ve düşük enerjili diyet (Low Calorie Diet [LCD]) modelinin kısa dönemdeki etkilerini incelemişler, VLCD’nin vücut ağırlık değişiminde ve glisemik kontrol sağlanmasında standart LCD'e kıyasla daha etkili olduğunu ve dört aylık bir süreçte uygulanmasının güvenli olduğunu belirtmişlerdir. Tip 2 diyabetli bireylerde enerji kısıtlaması yapılan (VLCD ve LCD) dokuz çalışmanın (4 randomize ve 5 randomize olmayan kontrollü çalışma, $n=346$ ) incelendiği bir meta-analizde de, VLCD’lerin üç aylık süreç sonunda açlık kan glukoz düzeylerinde istatistiksel olarak anlamlı düşme sağladığı bildirilmiştir (29). Alınan sonuçlar olumlu olsa da ADA <800 kkal/gün enerji içeren diyetlerin hastanın bu konuda deneyimli klinisyenler tarafından yakın klinik gözlem altında olması durumunda üç aya kadar uygulanabileceğini belirtmekte (9), Kanada Diyabet Derneği de <900 kkal/ gün enerji içeren diyetlerin rutin kullanımını, hasta medikal denetim altında olmadıkça önermemektedir (30).

Akdeniz diyetinin KV hastalık görülme riski üzerine etkisinin araştırıldığı, çok merkezli, medyan takip süresi 4.8 yll olan PREDIMED çalışmasında Akdeniz diyeti kapsamında zeytinyağı $(\mathrm{n}=96$, bir L/hafta zeytinyağl) ve sert kabuklu yemiş (n=83, 30 g/gün karışık sert kabuklu yemişler) tüketen iki çalışma grubu ve kontrol grubu ( $n=109$, diyet yağ alımını azaltmaları önerilmiştir) karşılaştırılmış ve her iki çalışma grubunda KV görülme riskinde \%30’luk azalma saptanmıştır (sırasıyla RR: 0.70; 0.53-0.91, $\mathrm{p}=0.009$, RR:0.70; 0.53-0.94, p = 0.02) (31). Qian et al. (32) yirmi dört çalışmanın sonuçlarını inceledikleri metaanalizde, yüksek tekli doymamış yağ asidi (TDYA) içeren diyetleri, yüksek karbonhidrat veya yüksek çoklu doymamış yağ asidi (ÇDYA) içeren diyetler ile karşılaştırmışlar ve yüksek TDYA'lı diyetin yüksek karbonhidratlı diyete kıyasla açlık kan glukozu, trigliserit, vücut ağırlığı ve sistolik kan basıncında, yüksek TDYA’lı diyetin yüksek ÇDYA’lı diyete kıyasla sadece açlık kan glukoz düzeylerinde istatistiksel olarak anlamlı düzeyde azalma sağladığı bildirilmiştir. Bu doğrultuda Amerikan Tıp Enstitüsü’nün (Institute of Medicine-IOM), yetişkin bireylerin diyetlerinde enerjinin \%20-35'inin yağdan karşlanmasının kabul edilebilir olduğunu belirttiği unutulmamalıdır (33). Benzer şekilde ADA da diyabetik bireylerde metabolik hedefler ve KVH riski açısından, tüketilen yağ çeşidinin, tüketilen yağ miktarından daha önemli olduğunu bu nedenle de diyette doymuş yağ asidi $(<\% 7)$ ve trans yağ asidi $(<\% 1)$ alımının azaltılmasını önermektedir (9,19). Aynı zamanda ADA'nın kanıta dayalı beslenme önerileri arasında, B kanıt düzeyinde diyabetli bireylerin, besinler yolu ile omega-3 yağ asitleri alımını artırmaları ve 2 porsiyon/hafta balık tüketmeleri, c kanıt düzeyinde ise total ve LDL kolesterol düzeylerinde azalmaya yardımcı olacağı için bitki stenol ve sterollerinden zengin besinlerin tüketimini dislipidemisi olan diyabetik bireylerin artırmaları (1.6-3 g/gün) yer almaktadır $(9,19)$.

Takip süresi en az on iki ay olan ve sekiz farklı vücut ağırlık kaybı yaklaşımının sonuçlarının incelendiği toplam on bir çalışmanın değerlendirildiği bir meta-analizde, obez tip 2 diyabet tanılı bireyler için glisemik kontrol, lipit ve kan basıncı düzeylerindeki olumlu sonuçları gözlemlemek için >\%5 vücut ağırlık kaybının gerekliliği belirtilmiş ve optimal sonuçların ise devamlılığı olan $\geq \% 7$ vücut ağırlık kaybı ile 
sağlanabileceği vurgulanmıştır (34). Benzer şekilde dokuz farklı diyet yaklaşımının tip 2 diyabet tanılı bireylerde $(n=4937)$ glisemik kontrol üzerindeki etkilerinin araştırıldığı, elli altı çalışmanın incelendiği bir başka meta-analizde, Akdeniz diyetinin tip 2 diyabet tanılı bireylerde glisemik kontrolün iyileştirilmesinde en etkili diyet yaklaşımı olduğu bildirilmiştir (35).

Karbonhidrat miktarı ve kalitesinin kardiyometabolik risk üzerine etkilerinin incelendiği bir derleme makalede de, enerji kısıtlaması vücut ağırlık kaybında primer etken olsa da, Akdeniz tipi beslenme veya düşük yağ-yüksek kompleks karbonhidrat içerikli diyet yaklaşımının diyabetin tedavisinde ve $\mathrm{KV}$ hastalık riskinin önlenmesinde daha etkili sonuçlar gösterdiği vurgulanmıştır. Aynı çalışmada, diyabetin önlenmesi ve tedavisinde mutlaka bireysel değerlendirme yapılması gerekliliği de ifade edilmiştir (36). Yoğun yaşam tarzı önerileri (diyet yağı enerjinin <\%30’u) ile klasik yaklaşımın vücut ağırlık kaybı süreci üzerine etkilerinin karşılaştırıldığı çok merkezli, 5145 tip 2 diyabetli birey ile yürütülen AHEAD (Action for Health in Diabetes) çalışması, müdahale grubunun birincil (KV nedenler, inme vb.) ve ikincil (koroner arter bypass graftı, konjestif kalp yetmezliği vb.) çıktılarda daha fazla azalma sağladığı ve yine aynı grupta fiziksel fonksiyonların ve yaşam kalitesi skorlarının daha yüksek ve medikal tedavi kullanımı ile harcamaların daha düşük olduğu bildirilmiştir (37).

\section{SONUÇ VE ÖNERILER}

Metabolik kontrolün sağlanması, diyabette tıbbi tedavinin ana bileşenidir. Beslenme tedavisi diyabetin yönetiminde tamamlayıcı bir role sahiptir ve tanı sonrasinda uygun beslenme tedavisi ile izlenen bireylerde metabolik kontrolün sağlanmasına katkı sağlamaktadır. Fazla kilolu ve obez diyabetli bireylerde vücut ağırlık kaybı ve optimal vücut ağırlığının sürdürülmesi önerilmektedir. Glisemik kontrolün iyileştirilmesi ve KVH riskinin azaltılması için altı ay içinde \%5-10 vücut ağırlık kaybı sağlanmalıdır. Vücut ağırlık kaybı yaklaşımı, genel olarak besin alımını azaltmak yerine yüksek karbonhidrat ve düşük posa içerikli, yüksek yağlı beslenme alışkanlıklarını değiştirmeyi ve oluşturulan sağlıklı öğün planının, fiziksel aktivite ve davranış değişikliği uygulamalarını içeren yaşam tarzı önerileri ile sunulmasını önermektedir. Diyetin makro besin ögesi içeriği, hastanın metabolik durumu ve besin tercihleri göz önünde bulundurularak bireye özgü ayarlanmalı ve TBT’de gerçekçi hedefler belirlenmelidir. Tedaviye uyum oranı yüksek bireyselleştirilmiş yaklaşımlar ile hedefe ulaşmak daha etkili olacaktır ve tedavide yaşam boyu multidisipliner yaklaşım benimsenmelidir.

Çıkar çatışması - Conflict of interest: Yazarlar çıkar çatışması olmadığını beyan ederler. - The authors declare that they have no conflict of interest.

\section{KAYNAKLAR}

1. Cho N, Shaw J, Karuranga S, Huang Y, da Rocha Fernandes J, Ohlrogge A, et al. IDF Diabetes Atlas: global estimates of diabetes prevalence for 2017 and projections for 2045. Diabetes Res Clin Pract 2018;138:271-81.

2. Lawes CM, Parag V, Bennett DA, Suh I, Lam TH, Whitlock G, Barzi F, Woodward M; Asia Pacific Cohort Studies Collaboration. Blood glucose and risk of cardiovascular disease in the Asia Pacific region. Diabetes Care. 2004 Dec;27(12):2836-42.

3. Khaw K-T, Wareham N, Bingham $\mathrm{S}$, Luben R, Welch A, Day N. Association of hemoglobin A1c with cardiovascular disease and mortality in adults: the European prospective investigation into cancer in Norfolk. Ann Intern Med. 2004;141(6):413-20.

4. American Diabetes Association. Obesity management for the treatment of type 2 diabetes. Diabetes Care. 2017;40 (Supplement 1):S57-S63.

5. Franz MJ, Boucher JL, Rutten-Ramos S, VanWormer JJ. Lifestyle weight-loss intervention outcomes in overweight and obese adults with type 2 diabetes: a systematic review and meta-analysis of randomized clinical trials. J Acad Nutr Diet. 2015;115(9):1447-63.

6. MacLeod J, Franz MJ, Handu D, Gradwell E, Brown C, Evert A, et al. Academy of Nutrition and Dietetics Nutrition practice guideline for type 1 and type 2 diabetes in adults: nutrition intervention evidence reviews and recommendations. J Acad Nutr Diet. 2017;117(10):1637-58.

7. Franz MJ, MacLeod J, Evert A, Brown C, Gradwell E, Handu D, et al. Academy of Nutrition and Dietetics Nutrition practice guideline for type 1 and type 2 diabetes 
in adults: systematic review of evidence for medical nutrition therapy effectiveness and recommendations for integration into the nutrition care process. J Acad Nutr Diet. 2017;117(10):1659-79.

8. Mitchell LJ, Ball LE, Ross LJ, Barnes KA, Williams LT. Effectiveness of dietetic consultations in primary health care: a systematic review of randomized controlled trials. J Acad Nutr Diet. 2017;117(12):1941-62.

9. Evert AB, Boucher JL, Cypress M, Dunbar SA, Franz MJ, Mayer-Davis EJ, et al. Nutrition therapy recommendations for the management of adults with diabetes. Diabetes Care. 2014;37(Supplement 1):S120-S43.

10. Franz MJ, Powers MA, Leontos C, Holzmeister LA, Kulkarni K, Monk A, et al. The evidence for medical nutrition therapy for type 1 and type 2 diabetes in adults. J Am Diet Assoc. 2010;110(12):1852-89.

11. Coppell KJ, Kataoka M, Williams SM, Chisholm AW, Vorgers SM, Mann JI. Nutritional intervention in patients with type 2 diabetes who are hyperglycaemic despite optimised drug treatment-Lifestyle Over and Above Drugs in Diabetes (LOADD) study: randomised controlled trial. BMJ. 2010;341:c3337.

12. Robbins JM, Thatcher GE, Webb DA, Valdmanis VG. Nutritionist visits, diabetes classes, and hospitalization rates and charges: the Urban Diabetes Study. Diabetes Care 2008;31(4):655-60.

13. Kirk JK, Graves DE, Craven TE, Lipkin EW, Austin M, Margolis KL. Restricted-carbohydrate diets in patients with type 2 diabetes: a meta-analysis. J Am Diet Assoc. 2008;108(1):91-100.

14. Dyson P. A review of low and reduced carbohydrate diets and weight loss in type 2 diabetes. J Hum Nutr Diet. 2008;21(6):530-8.

15. Snorgaard O, Poulsen GM, Andersen HK, Astr A. Systematic review and meta-analysis of dietary carbohydrate restriction in patients with type 2 diabetes. BMJ Open Diabetes Research and Care. 2017;5(1):e000354.

16. Meng Y, Bai H, Wang S, Li Z, Wang Q, Chen L. Efficacy of low carbohydrate diet for type 2 diabetes mellitus management: A systematic review and meta-analysis of randomized controlled trials. Diabetes Res Clin Pract. 2017;131:124-31.

17. Mansoor N, Vinknes KJ, Veierød MB, Retterstøl K. Effects of low-carbohydrate diets v. low-fat diets on body weight and cardiovascular risk factors: a meta-analysis of randomised controlled trials. Br J Nutr. 2016;115(3):46679.

18. Noto H, Goto A, Tsujimoto T, Noda M. Low-carbohydrate diets and all-cause mortality: a systematic review and meta-analysis of observational studies. PloS one. 2013;8(1):e55030.

19. American Diabetes Association. Lifestyle management: standards of medical care in diabetes-2018. Diabetes Care. 2018;41(Supplement 1):S38-S50.

20. Wang Q, Xia W, Zhao Z, Zhang H. Effects comparison between low glycemic index diets and high glycemic index diets on HbA1c and fructosamine for patients with diabetes: A systematic review and meta-analysis. Prim Care Diabetes. 2015;9(5):362-9.

21. Ojo O, Ojo OO, Adebowale F, Wang XH. The effect of dietary glycaemic index on glycaemia in patients with type 2 diabetes: A systematic review and metaanalysis of randomized controlled trials. Nutrients. 2018;10(3):373.

22. Thomas D, Elliott EJ. Low glycaemic index, or low glycaemic load, diets for diabetes mellitus. Cochrane Database Syst Rev. 2009:21(1):CDD06296.

23. Esfahani A, Wong JM, Mirrahimi A, Villa CR, Kendall CW. The application of the glycemic index and glycemic load in weight loss: A review of the clinical evidence. IUBMB Life. 2011;63(1):7-13.

24. FAO/WHO. Carbohydrates in human nutrition: Report of a Joint FAO/WHO Expert Consultation.Rome; 1997, Report No.:66.

25. Wang F, Zheng J, Yang B, Jiang J, Fu Y, Li D. Effects of vegetarian diets on blood lipids: a systematic review and meta-analysis of randomized controlled trials. Journal of the American Heart Association. 2015;4(10):e002408.

26. Le LT, Sabate J. Beyond meatless, the health effects of vegan diets: findings from the Adventist cohorts. Nutrients. 2014;6(6):2131-47.

27. Dinu M, Abbate R, Gensini GF, Casini A, Sofi F. Vegetarian, vegan diets and multiple health outcomes: A systematic review with meta-analysis of observational studies. Crit Rev Food Sci Nutr. 2017;57(17):3640-9.

28. Goday A, Bellido D, Sajoux I, Crujeiras AB, Burguera B, Garcia-Luna PP, et al. Short-term safety, tolerability and efficacy of a very low-calorie-ketogenic diet interventional weight loss program versus hypocaloric diet in patients with type 2 diabetes mellitus. NutrDiabetes. 2016;6(9):e230.

29. Rehackova L, Arnott B, Araujo-Soares V, Adamson A, Taylor R, Sniehotta F. Efficacy and acceptability of very low energy diets in overweight and obese people with Type 2 diabetes mellitus: a systematic review with metaanalyses. Diabet Med. 2016;33(5):580-91.

30. Cheng AY. Canadian Diabetes Association 2013 clinical practice guidelines for the prevention and management of diabetes in Canada. Introduction. Can J Diabetes. 2013;37 Suppl 1:S1-3.

31. Estruch R, Ros E, Salas-Salvadó J, Covas M-I, Corella D, Arós F, et al. Primary Prevention of Cardiovascular 
Disease with a Mediterranean Diet. New Eng J Med. 2013;368(14):1279-90.

32. Qian F, Korat AA, Malik V, Hu FB. Metabolic effects of monounsaturated fatty acid-enriched diets compared with carbohydrate or polyunsaturated fatty acidenriched diets in patients with type 2 diabetes: a systematic review and meta-analysis of randomized controlled trials. Diabetes Care. 2016;39(8):1448-57.

33. Trumbo P, Schlicker S, Yates AA, Poos M. Dietary reference intakes for energy, carbohydrate, fiber, fat, fatty acids, cholesterol, protein and amino acids. J Acad Nutr Diet. 2002;102(11):1621.

34. Franz MJ, Boucher JL, Rutten-Ramos S, VanWormer JJ. Lifestyle weight-loss intervention outcomes in overweight and obese adults with type 2 diabetes: a systematic review and meta-analysis of randomized clinical trials. J Acad Nutr Diet. 2015;115(9):1447-63.

35. Schwingshackl L, Chaimani A, Hoffmann G, Schwedhelm $\mathrm{C}$, Boeing $\mathrm{H}$. A network meta-analysis on the comparative efficacy of different dietary approaches on glycaemic control in patients with type 2 diabetes mellitus. Eur J Epidemiol. 2018;33(2):157-70.

36. Blaak EE. Carbohydrate quantity and quality and cardio-metabolic risk. Curr Opin Clin Nutr Metab Care. 2016;19(4):289-93.

37. AHEAD Research Group. Eight-year weight losses with an intensive lifestyle intervention: the look AHEAD study. Obesity (Silver Spring). 2014;22(1):5-13. 